\title{
Ascorbic Acid Enhances Tet-Mediated 5-Methylcytosine Oxidation and Promotes DNA Demethylation in Mammals
}

Ruichuan Yin, ${ }^{\dagger}$ Shi-Qing Mao, ${ }^{\ddagger}$ Bailin Zhao, ${ }^{\dagger}$ Zechen Chong, ${ }^{\S, \perp}$ Ying Yang, ${ }^{\S, \perp}$ Chao Zhao, ${ }^{\dagger}$ Dapeng Zhang, ${ }^{\dagger}$ Hua Huang, ${ }^{\dagger}$ Juan Gao, ${ }^{\ddagger}$ Zheng Li, ${ }^{\dagger}$ Yan Jiao, ${ }^{\|}$Cuiping Li, ${ }^{\dagger}$ Shengquan Liu, ${ }^{\dagger}$ Danni Wu, Weikuan Gu, ${ }^{\Uparrow}$ Yun-Gui Yang, ${ }^{\S, \perp}$ Guo-Liang Xu, ${ }^{\ddagger}$ and Hailin Wang* ${ }^{* \dagger}$

${ }^{\dagger}$ The State Key Laboratory of Environmental Chemistry and Ecotoxicology, Research Center for Eco-Environmental Sciences, Chinese Academy of Sciences, Beijing 100085, China

${ }^{\ddagger}$ Group of DNA Metabolism, The State Key Laboratory of Molecular Biology, Institute of Biochemistry and Cell Biology, Shanghai Institutes for Biological Sciences, Chinese Academy of Sciences, Shanghai 200031, China

${ }^{\S}$ Disease Genomics and Individualized Medicine Laboratory, Beijing Institute of Genomics, Chinese Academy of Sciences, Beijing 100101, China

"Department of Orthopaedic Surgery, University of Tennessee Health Science Center, Memphis, Tennessee 38163, United States

${ }^{\perp}$ University of Chinese Academy of Sciences, Beijing 100039, China

Supporting Information

ABSTRACT: DNA hydroxymethylation and its mediated DNA demethylation are critical for multiple cellular processes, for example, nuclear reprogramming, embryonic development, and many diseases. Here, we demonstrate that a vital nutrient ascorbic acid (AA), or vitamin $\mathrm{C}(\mathrm{Vc})$, can directly enhance the catalytic activity of Tet dioxygenases for the oxidation of 5methylcytosine $(5 \mathrm{mC})$. As evidenced by changes in intrinsic fluorescence and catalytic activity of Tet 2 protein caused by AA and its oxidation-resistant derivatives, we further show that AA can uniquely interact with the C-terminal catalytic domain of Tet enzymes, which probably promotes their folding and/or recycling of the cofactor $\mathrm{Fe}^{2+}$. Other strong reducing chemicals do not have a similar effect. These results suggest that AA also acts as a cofactor of Tet enzymes. In mouse embryonic stem cells, AA significantly increases the levels of all $5 \mathrm{mC}$ oxidation products,

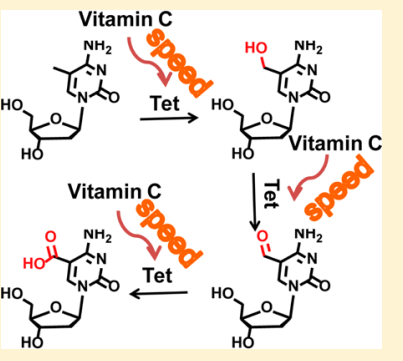
particularly 5-formylcytosine and 5-carboxylcytosine (by more than an order of magnitude), leading to a global loss of $5 \mathrm{mC}$ ( $\sim 40 \%)$. In cells deleted of the Tet 1 and Tet 2 genes, AA alters neither $5 \mathrm{mC}$ oxidation nor the overall level of $5 \mathrm{mC}$. The AA effects are however restored when Tet 2 is re-expressed in the Tet-deficient cells. The enhancing effects of AA on $5 \mathrm{mC}$ oxidation and DNA demethylation are also observed in a mouse model deficient in AA synthesis. Our data establish a direct link among AA, Tet, and DNA methylation, thus revealing a role of AA in the regulation of DNA modifications.

\section{INTRODUCTION}

DNA demethylation remarkably contributes to the dynamics of the epigenetic marker 5-methylcytosine $(5 \mathrm{mC})$ in mammals and is critical for multiple biological processes, including animal cloning, ${ }^{1}$ nuclear reprogramming, ${ }^{2,3}$ development, ${ }^{4-8}$ and highly locus-specific regulation of gene activities. ${ }^{9-11}$ DNA demethylation can be initiated by the oxidation of $5 \mathrm{mC}$ and the formation of 5-hydroxymethylcytosine $(5 \mathrm{hmC})$, which are catalyzed by ten eleven translocation (Tet) family dioxygenases. ${ }^{12-15}$ The formed $5 \mathrm{hmC}$ can be diluted by DNA replication, suggesting a passive DNA demethylation pathway. ${ }^{16}$ Moreover, the $5 \mathrm{hmC}$ can be further oxidized by Tet proteins to form 5-formylcytosine (5fC) and 5-carboxylcytosine $(5 \mathrm{caC})$, which can be excised by thymine DNA glycosylase (TDG) followed by the reintroduction of unmethylated cytosine through the base-excision repair (BER) pathway. ${ }^{14,15}$ This important pathway for active DNA demethylation has been thought to be involved in a number of prominent biological processes. ${ }^{5,6,10,11}$ Early and recent studies suggested that active and replication-independent DNA demethylation might be a rapid process. ${ }^{10,11}$ The radically altered methylation, as observed in replication-independent demethylation of the paternal genome in zygotes, may complete within hours. $^{5,6,17-19}$ However, the observed levels of the active DNA demethylation intermediates, $5 \mathrm{fC}$ and $5 \mathrm{caC}$ in the cultured cells, were 100 -fold less than the primary product 5 hmC. ${ }^{13-15,20-22}$

Biochemically, the Tet-mediated DNA demethylation process should be irreversible because no replication-dependent mechanism is found to resynthesize $5 \mathrm{mC}$ oxidation products. However, the levels of both $5 \mathrm{hmC}$ and $5 \mathrm{mC}$ are relatively stable in normal mammalian tissues. ${ }^{23}$ On the other hand, the landscapes of $5 \mathrm{mC}$ and $5 \mathrm{hmC}$ are altered in many diseases. ${ }^{23}$ These observations implicate the biological importance of maintaining $5 \mathrm{mC}$ and $5 \mathrm{hmC}$ in various tissues. But, little is known on how cells maintain the levels of the $5 \mathrm{mC}$ oxidation products. The regulation mechanisms remain poorly under-

Received: March 20, 2013

Published: June 14, 2013 
stood. This prompted us to seek a new chemical factor that may regulate DNA methylation and $5 \mathrm{hmC}$ formation.

The catalytic activity of Tet dioxygenases for $5 \mathrm{mC}$ oxidation requires two cofactors, iron(II) and 2-ketoglutarate. Ascorbic acid (AA), serving for some nonheme iron dioxygenases (e.g., prolyl 4-hydroxylases) to rescue the enzyme by reducing the inactive iron(III) state, ${ }^{24}$ might be another cofactor for Tet proteins. However, in vitro oxidation reactions previously suggested that the active Tet1 fragment would not act like prolyl 4-hydroxylase, ${ }^{12}$ which may suddenly lose all the catalytic activity in the absence of $\mathrm{AA},{ }^{24}$ and its catalytic activity is not significantly affected by AA.

Interestingly, AA could induce DNA demethylation at the cellular level. $^{25-29}$ Limited data suggested that this effect was probably associated with histone demethylases. ${ }^{28}$ Since the histone-targeting demethylases cannot directly act on methylated DNA, we speculate that AA should be a better choice to be exploited by Tet dioxygenases to regulate DNA demethylation. The natural choice of nutrient AA would not sacrifice normal cellular functions in mammals. Chemically, the Tet oxidation activity could be efficiently regulated by changing the level of the known cofactor iron(II), but which may induce severe deleterious effects if not tightly controlled in mammals. ${ }^{30}$

Here, we hypothesize that AA may enhance Tet-mediated oxidation of $5 \mathrm{mC}$ and provide unique capacity of regulating the dynamics of DNA methylation. To test our hypothesis, we systematically investigated the effects of $\mathrm{AA}$ on the catalytic activity of Tet proteins, $5 \mathrm{mC}$ oxidation, and DNA demethylation and the underlying mechanisms. Our results provide new mechanistic insights into the biochemical role of AA and the change of DNA methylation in development, diseases, and regenerative therapies.

\section{RESULTS}

AA Directly Enhances in Vitro Oxidation Activity of Tet Dioxygenases. We first purified the C-terminal catalytic domain (CD) of the Tet 2 protein from overexpressing cells (Supporting Information, Figure S1A) and investigated the in vitro $5 \mathrm{mC}$ oxidation in genomic DNA. The levels of $5 \mathrm{mC}$ and $5 \mathrm{mC}$ oxidation products were detected by a newly developed assay using ultrahigh performance liquid chromatography-triple quadrupole mass spectrometry coupled with multiple-reaction monitoring (UHPLC-MRM-MS/MS, Supporting Information). Previously, AA was not shown to have any significant enhancement on the Tet1-mediated oxidation in in vitro reactions. $^{12}$ In those reactions, $100 \mu \mathrm{M} \mathrm{Fe}^{2+}$ was used. We reexamined the reactions by the use of $\mathrm{Fe}^{2+}$ at physiologically relevant concentration $(10 \mu \mathrm{M}){ }^{30}$ Excess dithiothreitol (1.0 $\mathrm{mM}$ ) was also included in all tested reaction solutions. Under such conditions, we observed the formation of $5 \mathrm{hmC}$ and $5 \mathrm{fC}$ in the presence of the purified Tet $2 \mathrm{CD}$ but without AA (Figure $1 \mathrm{~A}$ and the Supporting Information, Figure S1B). Upon addition of $\mathrm{AA}(50-500 \mu \mathrm{M})$, the levels of $5 \mathrm{hmC}$ and $5 \mathrm{fC}$ increased in a dose-dependent manner by $4.0-7.0$-fold and by 4.6-8.9-fold (Figure 1A,B), respectively. Time-course studies of $5 \mathrm{hmC}$ and $5 \mathrm{fC}$ formation showed that AA could accelerate the reactions (Figure $1 \mathrm{C}$ ). The reaction rates for producing $5 \mathrm{hmC}$ and $5 \mathrm{fC}$ increased by 8.2- and 6.2-fold (Supporting Information, Figure S2), respectively. Accompanying with the increase in $5 \mathrm{hmC}$ and $5 \mathrm{fC}$, there is a significant decrease in the $5 \mathrm{mC}$ level due to the oxidation of $5 \mathrm{mC}$ (Figure 1D).
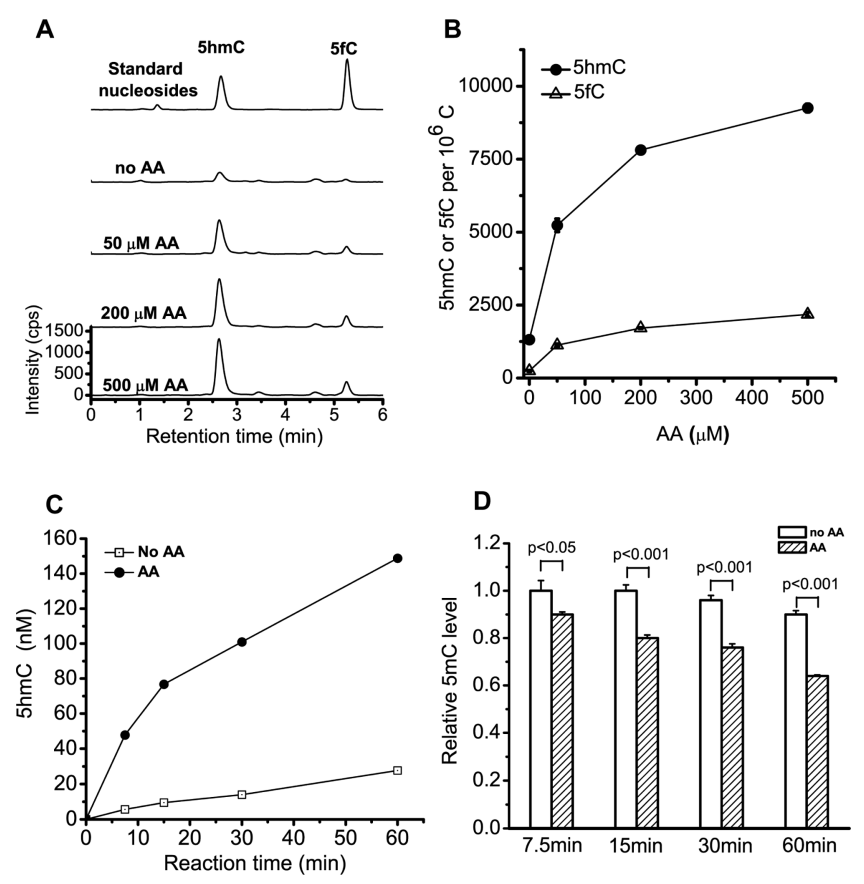

Figure 1. AA stimulates Tet-catalyzed $5 \mathrm{mC}$ oxidation in vitro. (A) UHPLC-MRM-QQQ detection of $5 \mathrm{hmC}$ and $5 \mathrm{fC}$ in methylated lambda DNA oxidized by purified Tet2 CD. (B) AA dose-dependent formation of $5 \mathrm{hmC}$ and $5 \mathrm{fC}$ in methylated lambda DNA oxidized by purified Tet2 CD. (C) AA-induced stimulation of the reaction rate of Tet2 CD oxidizing $5 \mathrm{mC}$ to $5 \mathrm{hmC}$. (D) Reduction in the $5 \mathrm{mC}$ level caused by AA-enhanced Tet oxidation.

Similarly, AA can stimulate the activity of the purified Tet1 $\mathrm{CD}$ to significantly increase the production of $5 \mathrm{hmC}$ and $5 \mathrm{fC}$ (Supporting Information, Figure S3).

As described above, AA-enhanced $5 \mathrm{mC}$ oxidation can be observed using the purified CD domains of Tet 1 and Tet2. Since the CD domains of Tet proteins are conserved, ${ }^{12,13}$ these results indicate that $\mathrm{AA}$ may directly interact with the $\mathrm{CD}$ domain of Tet proteins to enhance $5 \mathrm{mC}$ oxidation.

Interestingly, a number of strong reducing chemicals (spermidine, vitamin $\mathrm{B} 1$, vitamin $\mathrm{E}$, glutathione, $\mathrm{NADPH}$, and L-cysteine) cannot enhance the Tet-mediated oxidation of $5 \mathrm{mC}$ (Supporting Information, Figure S4). This suggests that $\mathrm{AA}$ is a unique cofactor of Tet dioxygenases, which cannot be simply replaced by other reducing chemicals. Alternatively, those reducing chemicals may not have an ability to reduce $\mathrm{Fe}^{3+}$ to $\mathrm{Fe}^{2+}$ for iron(II) recycling during Tet-mediated oxidation of $5 \mathrm{mC}$.

To further understand the effect of $\mathrm{AA}$, we tested the preincubation of Tet dioxygenases in the presence and absence of AA under aerobic and anaerobic conditions. We find that AA can stimulate Tet-mediated oxidation of $5 \mathrm{mC}$ and enhance formation of $5 \mathrm{hmC}$ and $5 \mathrm{fC}$ no matter whether Tet is preincubated with or without oxygen, further supporting the direct stimulation of Tet enzymes by AA (see the Supporting Information, Figure S4C,D).

On the other hand, the above preincubation results suggest that the reactions are enhanced even by the presence of $\mathrm{AA}$ during the preincubation of Tet enzymes (Supporting Information, Figure S4C,D), suggesting that AA is needed in very turnover of Tet-mediated oxidation of $5 \mathrm{mC}$. This was also supported by the results obtained from the time course of Tet2CD-mediated oxidation of $5 \mathrm{mC}$, showing the enhance- 
ment effect of AA started from the first time point (Figure 1C and the Supporting Information, Figure S2).

Binding of AA to CD Domain of Tet Enzymes. It is not clear how AA enhances the catalytic activity of Tet proteins. To understand the underlying mechanism, we studied the interactions of AA with the conserved $\mathrm{CD}$ domains of Tet proteins. The Tet2 CD contains 5 tryptophan (W) and 35 tyrosine $(\mathrm{Y})$ residues, ${ }^{12}$ which are known to emit intrinsic fluorescence. $^{31}$ Indeed, we observed a strong fluorescence signal (maximum emission: $303 \mathrm{~nm}$ ) with an excitation of 280 $\mathrm{nm}$ for the Tet2 CD at $20 \mathrm{nM}$ (Figure 2A). Tryptophan-related
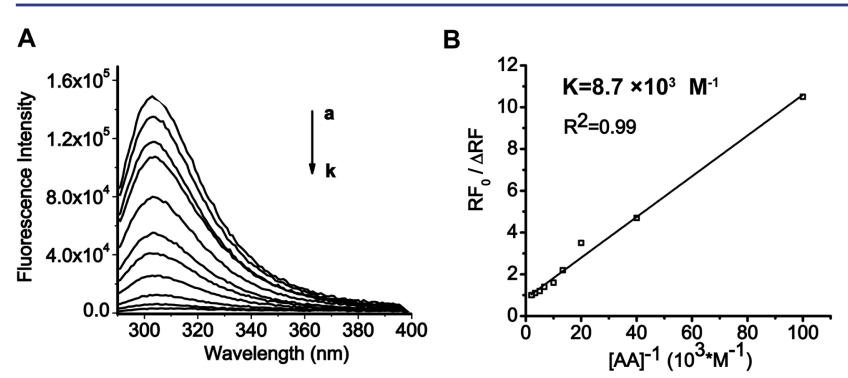

C

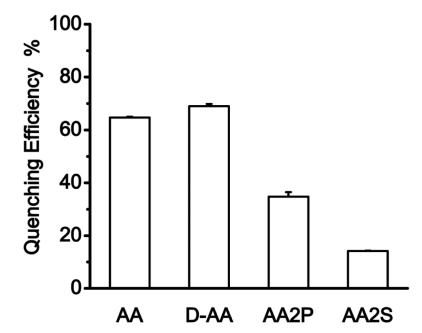

D

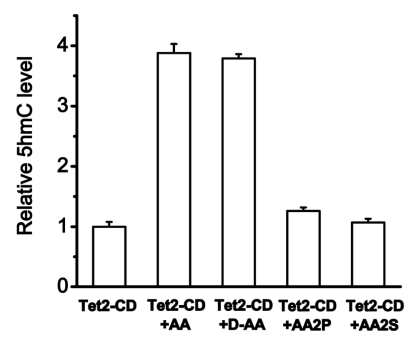

Figure 2. Interaction of $\mathrm{AA}$ with the Tet $2 \mathrm{CD}$ and its stimulation of the Tet2 CD catalytic activity. (A) Fluorescence quenching of the Tet $2 \mathrm{CD}$ caused by AA at varying concentrations $(\mathrm{a}, 0 \mu \mathrm{M} ; \mathrm{b}, 10 \mu \mathrm{M}$; c, $25 \mu \mathrm{M}$; d, $50 \mu \mathrm{M}$; e, $75 \mu \mathrm{M}$; f, $100 \mu \mathrm{M} ; \mathrm{g}, 150 \mu \mathrm{M}$; h, $200 \mu \mathrm{M}$; , $300 \mu \mathrm{M} ; \mathrm{j}, 400 \mu \mathrm{M} ; \mathrm{k}, 500 \mu \mathrm{M})$. (B) Modified Stern-Volmer plot for estimating the binding constant of $\mathrm{AA}$ and the Tet2 $\mathrm{CD}$. (C) Fluorescence quenching of the Tet $2 \mathrm{CD}$ caused by AA and its analogues at $100 \mu \mathrm{M}$. (D) Stimulation of the Tet2 CD catalytic activity by $\mathrm{AA}$ and its analogues.

fluorescence (300-400 nm) was barely detected by an excitation at $295 \mathrm{~nm}$. AA efficiently quenched the intrinsic fluorescence of the Tet2 CD, which is supposed to be mainly associated with the tyrosine residues, in a concentrationdependent manner. In contrast, the collision-caused quenching is negligible using acrylamide at a 100-times higher concentration $(5.0 \mathrm{mM})$ (Supporting Information, Figure S5). This indicates that AA can directly interact with the CD domain of Tet proteins. The estimated binding constant is about $8.7 \times 10^{3} \mathrm{M}^{-1}$ (Figure 2B).

Interestingly, the quenching of the intrinsic fluorescence of the Tet $2 \mathrm{CD}$ is almost complete ( $98 \%$ for $500 \mu \mathrm{M} \mathrm{AA})$. Recent work using NMR and fluorescence anisotropy proved that similar fluorescence quenching caused by iron(II) and 2ketoglutarate is linked to the change in the protein dynamics of a dioxygenase $A \mathrm{kBB},{ }^{32}$ rendering the full catalytic activity to the enzyme. Therefore, our intrinsic fluorescence quenching data may also suggest that the unique interaction of $A A$ with the $C D$ domain of Tet enzymes probably promotes their folding, which favors the catalytic activity of Tet enzymes and accelerates the Tet-mediated oxidation reactions.
We further tested three AA analogues, one stereoisomer (DAA, D-isoascorbic acid) and two oxidation-resistant derivatives (AA2P, L-ascorbic acid 2-phosphate; AA2S, L-ascorbic acid 2sulfate). The chemical structures were shown in the Supporting Information, Figure S6. At the same tested concentration (100 $\mu \mathrm{M})$, D-AA caused slightly higher fluorescence quenching efficiency than AA, indicating an interaction of D-AA with the Tet2 CD (Figure 2C). Meanwhile, D-AA also caused an enhancement ( 3.8 fold) for stimulating the Tet2 CD catalytic activity as high as AA (Figure 2D). In contrast, AA2P and AA2S caused 2- or 5-fold lower fluorescence quenching efficiency than D-AA (Figure 2C), suggesting a much weaker interaction with the Tet 2 CD. Notably, AA2P and AA2S showed negligible stimulation for the catalytic activity of Tet2 (Figure 2D). All these results consistently support the important role of the interaction of AA with the CD of Tet 2 in the stimulation of its catalytic activity.

Alternatively, the direct interaction of AA with Tet proteins may facilitate the recycling of the cofactor $\mathrm{Fe}^{2+}$ by reducing the intermediate $\mathrm{Fe}^{3+}$ to $\mathrm{Fe}^{2+}$ during Tet-mediated oxidation of $5 \mathrm{mC}$.

AA Stimulates Formation of Active $5 \mathrm{mC}$ Oxidation Products in Tet-Transfected Cells. The chemical environment in mammalian cells is very complex, and a multitude of small and bioactive molecules coexist. These small biomolecules might interfere with the stimulation effects of AA on Tetmediated oxidation. Therefore, we examined the influence of AA on Tet-deficient cells transfected with an expression vector for either the full length Tet2 cDNA or cDNA for the Tet2 CD. Compared with untransfected cells, the level of $5 \mathrm{hmC}$ was significantly elevated (3.4- and 5.1-fold) in the cells complemented with full-length and the $\mathrm{CD}$ of Tet2 (Figure $3 \mathrm{~A}, \mathrm{~B}$ and the Supporting Information, Figure S7), even in the absence of AA treatment. After $24 \mathrm{~h}$ exposure to $100 \mu \mathrm{M}$ AA, the level of $5 \mathrm{hmC}$ further increased 2.6-fold in the complemented cells (Figure 3B). Similarly, 5fC could be observed in the genomic DNA of the transfected cells, and its level increased 8.8- and 5.2-fold after AA treatment (Figure $3 \mathrm{~A}, \mathrm{C}$ and the Supporting Information, Figure S7). Accompanying with the increase in $5 \mathrm{mC}$ oxidation products, a significant decrease in $5 \mathrm{mC}$ was observed in cells transfected with the full length Tet 2 cDNA and the Tet2 CD cDNA (Figure 3D). These results provide strong evidence that AA can enhance Tet-mediated oxidation and induce DNA demethylation at the cellular level.

Interestingly, an increase in $5 \mathrm{hmC}$ in the control cells after addition of AA was also observed (Figure 3B). This is probably associated with the constitutive expression of residual Tet enzymes, by which AA may increase the $5 \mathrm{hmC}$ formation in the tested control cells.

AA Stimulates Formation of Active $5 \mathrm{mC}$ Oxidation Products in ES Cells. To investigate biological relevance of the observed AA enhancement on Tet activity, we then measured $5 \mathrm{mC}$ oxidation products in Tet-proficient embryonic stem (ES) cells. The frequency of $5 \mathrm{hmC}$ in genomic DNA of untreated mouse ES cells was about $8.9 \times 10^{2}$ per million C. Treatment of cells with $100 \mu \mathrm{M}$ AA over $24 \mathrm{~h}$ increased the level of $5 \mathrm{hmC} 3.7$-fold to $3.31 \times 10^{3}$ per million C (Figure $4 \mathrm{~A}$ ). The identity of $5 \mathrm{hmC}$ was validated using high-resolution mass spectrometry analysis. The corresponding fractions collected from UHPLC separation of digested genomic DNA of the untreated and AA-treated cells had accurate mass/charge ratios of 258.1080 and $258.1092(\mathrm{M}+\mathrm{H})$, which match the theoretic 


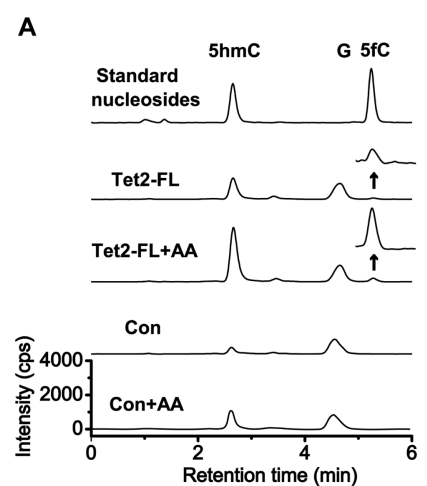

B

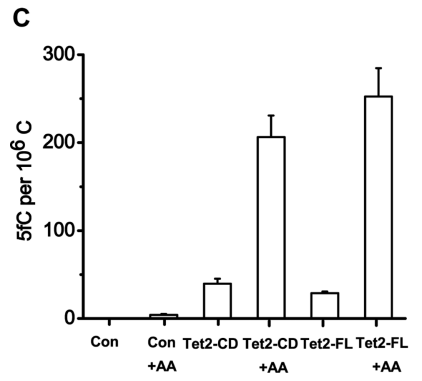

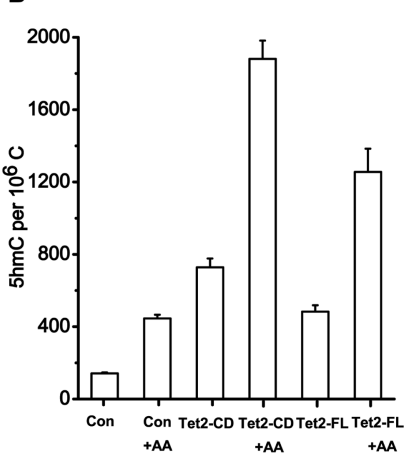

D

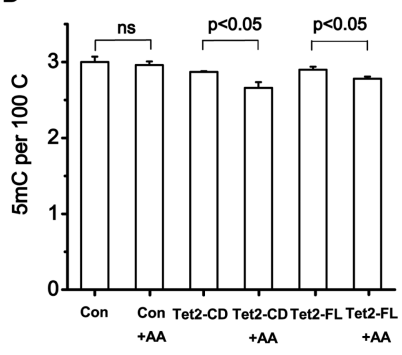

Figure 3. AA enhances Tet-mediated $5 \mathrm{mC}$ oxidation in transfected human HEK293T cells. (A) UHPLC-MRM-QQQ detection of $5 \mathrm{hmC}$ and 5fC in genomic DNA of Tet2-transfected HEK293T cells. (B) $5 \mathrm{hmC}$ in AA-treated (+) or untreated (-) HEK293T cells expressing full-length Flag-Tet2 (Tet2-FL) or the C-terminal CD of Tet2 (Tet2 CD). The HEK293T cells not expressing Flag-Tet2 were used as control cells (Con). (C) $5 \mathrm{fC}$ in AA-treated (+) or untreated (-) HEK293T cells expressing Flag-Tet2. (D) AA reduces the level of $5 \mathrm{mC}$ in genomic DNA of Tet2 CD-transfected HEK293T cells. Student $t$ test was used for evaluation of statistical significance. "ns" indicates no significant difference.

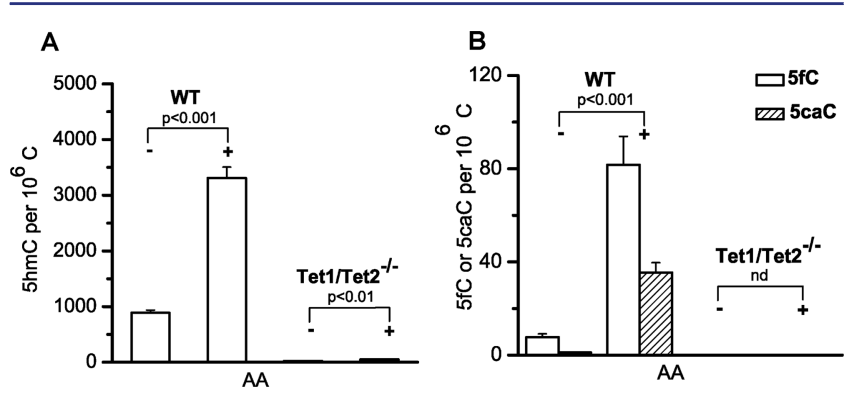

Figure 4. (A) Increase of $5 \mathrm{hmC}$ in wild-type but not in Tet-deficient ES cells treated with AA. (B) Acceleration of active DNA demethylation by the increase of $5 \mathrm{fC}$ and $5 \mathrm{caC}$ in $\mathrm{ES}$ cells treated with AA. "nd" indicates "not detectable". Student $t$ test was used for evaluation of statistical significance.

monoisotopic mass of $5 \mathrm{hmC}$ (258.1084) with a deviation of 1.6-4.0 ppm (Supporting Information, Figure S8). We further examined $5 \mathrm{hmC}$ using T4-glucosyltransferase-catalyzed glucosylation, ${ }^{33}$ which converts $5 \mathrm{hmC}$ in genomic DNA to glucosyl5-hydroxymethylcytosine (5ghmC) detectable by UHPLCMRM-QQQ analysis monitoring a transition pair of $\mathrm{m} / \mathrm{z} 420$ $\rightarrow$ 304. Indeed, the $5 \mathrm{hmC}$ peak completely disappeared, and a new peak corresponding to the glucosylated product ( $5 \mathrm{ghmC}$ ) appeared for the genomic DNA from both AA-treated and untreated ES cells (Supporting Information, Figure S9A,B), but the level of glucosylated $5 \mathrm{hmC}$ in AA-treated ES cells was 4fold higher than that in untreated ES cells (Supporting

Information, Figure S9C). These results consistently support the AA-induced increase of $5 \mathrm{hmC}$ in mouse ES cells.

The primary $5 \mathrm{mC}$ oxidation product $5 \mathrm{hmC}$ does not lead to demethylation on its own, but it can cause replicationdependent passive demethylation. ${ }^{16}$ On the other hand, the generated $5 \mathrm{hmC}$ can initiate active DNA demethylation by further oxidation, forming $5 \mathrm{fC}$ and $5 \mathrm{caC} .^{14,15,34}$ The presence of $5 \mathrm{fC}$ and $5 \mathrm{caC}$ essentially indicates the occurrence of active DNA demethylation. Importantly, accompanying with significant increase in $5 \mathrm{hmC}(\sim 4.0$-fold $)$, we also found that the level of $5 \mathrm{fC}$ in mouse ES cells was elevated from $7.7 \pm 1.4$ (untreated) to $81.7 \pm 12.2$ per million $\mathrm{C}$ after $\mathrm{AA}$ treatment (Figure 4B and the Supporting Information, Figure S10A), that is, a greater than 10.6-fold increase. Similarly, the level of $5 \mathrm{caC}$ was found to be elevated by 20 -fold after AA treatment (Figure $4 \mathrm{~B}$ and the Supporting Information, Figure S10B). The dramatic increase in $5 \mathrm{fC}$ and $5 \mathrm{caC}$ in AA-treated ES cells demonstrates a critical role of AA in active DNA demethylation.

We further posited that the large increase in the amount of $5 \mathrm{hmC}, 5 \mathrm{fC}$, and $5 \mathrm{caC}$ induced by AA treatment may result from the enhanced Tet-mediated $5 \mathrm{mC}$ oxidation. In Tet $1 /$ Tet 2 double knockout mouse ES cells, $5 \mathrm{hmC}$ was barely detectable after AA treatment (Figure 4A and the Supporting Information, Figure $\mathrm{S} 10 \mathrm{~A}$ ), as were $5 \mathrm{fC}$ and $5 \mathrm{caC}$ (Figure $4 \mathrm{~B}$ and the Supporting Information, Figure S10).

To test whether AA changes the expression of Tet enzymes, we used real-time qPCR to evaluate the mRNA level of Tet1 in mouse ES cells. Tet1 is the predominant Tet enzyme in mouse ES cells. ${ }^{50}$ No significant change in the expression of TET 1 was observed (see the Supporting Information, Figure S11). These results further support that AA directly influences the catalysis of Tet.

Taken together, our data show that AA can directly enhance Tet-mediated $5 \mathrm{mC}$ oxidation and promote DNA hydoxymethylation by forming $5 \mathrm{hmC}$ and activate DNA demethylation by forming $5 \mathrm{fC}$ and $5 \mathrm{caC}$ in Tet-proficient ES cells.

AA Induces Tet-Dependent DNA Demethylation in ES Cells. To investigate the consequence of AA-enhanced Tetmediated $5 \mathrm{mC}$ oxidation, we further measured the level of $5 \mathrm{mC}$ in the genomic DNA of mouse ES cells treated with or without AA. After treating ES cells with $100 \mu \mathrm{M}$ AA for 1 day, the level of $5 \mathrm{mC}$ decreased by $13 \%$. By further treating cells for 2-3 days, the level of $5 \mathrm{mC}$ decreased by $32-40 \%$ (Figure $5 \mathrm{~A}$ ). These results indicate that $\mathrm{AA}$ can stimulate a dramatic erasure of $5 \mathrm{mC}$ in the genomic DNA of ES cells. The erasure of $5 \mathrm{mC}$ by AA was further validated by HPLC-UV analysis (Supporting Information, Figure S12). Previously, significant loss of $5 \mathrm{mC}$ has been reported at two developmental stages: erasure of somatic imprinting in primordial germ cells and rapid demethylation of the paternal pronucleus in zygotes. ${ }^{4}$ However, these two large-scale demethylation events are linked with reprogramming of genomic methylation patterns. Alternatively, $5 \mathrm{mC}$ is largely erased by inhibiting or eliminating the activity of DNA methyltransferases. ${ }^{35}$ Here, we show a global loss of the $5 \mathrm{mC}(\sim 2 / 5)$ in ES cells without undergoing nuclear reprogramming and without inhibiting DNA methylation. This finding expands earlier observations that showed an AAinduced demethylation of specific genes. ${ }^{25,26}$ In contrast to the wild-type of murine ES cells, the Tet1/Tet 2 double knockout showed minor reduction in $5 \mathrm{mC}$ following exposure to AA (Figure 5B). These results indicate that AA can induce DNA demethylation mainly by enhancing the Tet-mediated oxidation of $5 \mathrm{mC}$. 

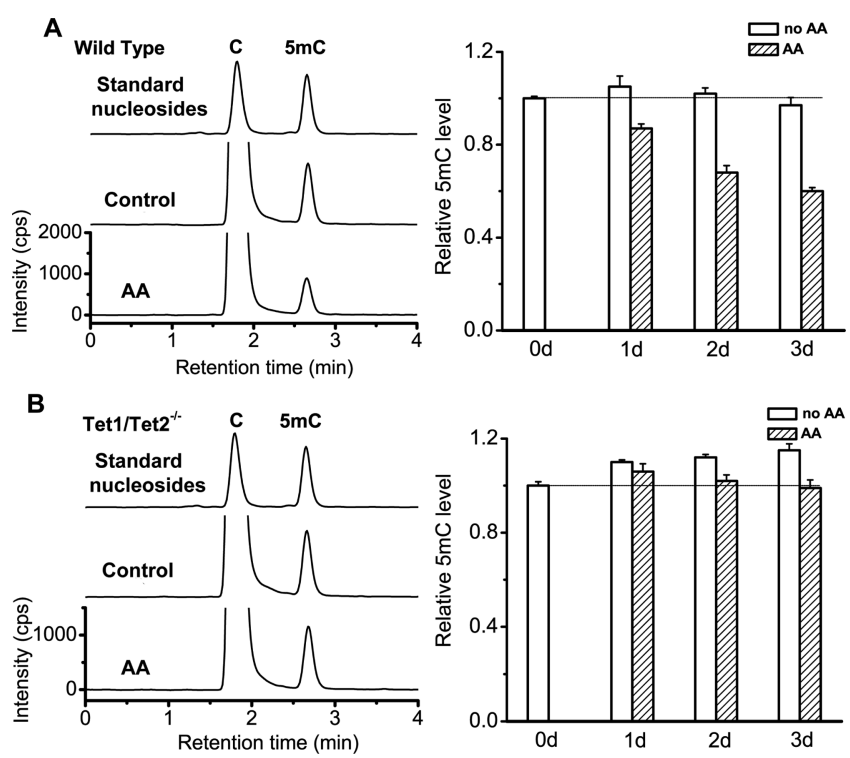

Figure 5. AA enhances DNA demethylation in a Tet-dependent manner in mouse ES cells. (A) UHPLC-MRM-QQQ detection of $5 \mathrm{mC}$ (left) and the measured frequency of $5 \mathrm{mC}$ (right) in the genomic DNA of wild-type (WT) ES cells treated with AA or without AA (control) for 1-3 days. Only UHPLC-MS traces were shown for 3 days $(72 \mathrm{~h})$. (B) The Tet $1 /$ Tet 2 double knockout $\left(\operatorname{Tet} 1 / \operatorname{Tet}^{-/-}\right)$ eliminates AA-induced 5mC erasure in ES cells. UHPLC-MRM-QQQ traces of $5 \mathrm{mC}$ (left) and the measured frequency of $5 \mathrm{mC}$ (right) were shown for 3 days culture and 1-3 days culture, respectively.

The observation of the slight reduction in $5 \mathrm{mC}$ caused by AA in Tet1/Tet2-deleted cells (Figure 5B) suggests one Tetunrelated but minor mechanism for AA-induced DNA demethylation, which is probably related to histone demethylases ${ }^{28}$

AA Regulates a Potential Broad Functional Pathway by $5 \mathrm{hmC}$ Formation. To further explore the roles of AA on DNA modifications, we examined the genome-wide distribution and enrichment of $5 \mathrm{hmC}$ in mouse ES cells using a selective chemical labeling of $5 \mathrm{hmC}$ pull-down approach ${ }^{33}$ coupled with deep-sequencing by Illumina HiSeq 2000 platform. Using MACS, ${ }^{33}$ we found a total of 12525 peaks in
AA-treated cells and 6625 peaks in the control $\left(p<10^{-5}\right.$, fold enrichment $>10$ ). In every genomic feature (Figure 6A), the enrichment of $5 \mathrm{hmC}$ is approximate to 2 -fold in AA-treated cells as compared to that of the control. To explore the potential functions of the elevated $5 \mathrm{hmC}$, we compared the distribution of $5 \mathrm{hmC}$ (Figure 6B) within the gene regions and their up- and downstream regions between the AA-treated and the control. In particular, we observed that AA increased the abundance of $5 \mathrm{hmC}$ near transcription start sites (TSS) (Figure $6 \mathrm{~B}$ and the Supporting Information, Figure S13A), suggesting a mechanism for the regulation of gene expression by AA. On the basis of gene ontology (GO) and enrichment analysis (Supporting Information, Figure S13B), 545 genes were enriched in functional pathways related to differentiation and various organ development (including brain, muscle, heart, blood, epithelium, etc.), phosphorylation, protein biosynthesis and complex assembly, behavior, transport, cell cycle, and cell signaling, indicating a potential broad regulatory function of 5 hmC formation by AA.

Interestingly, our previous work showed that $\mathrm{sfx} / \mathrm{sfx}$ mice deficient in AA synthesis, if without AA supplement, suffered from a number of developmental problems, for example, a loss of body weight, larger brain and kidney, smaller spleen and thymus, abnormal red blood cells and white blood cells, and reduced osteocalcin. ${ }^{36}$ Although the heart, liver, and testes were not affected in $\mathrm{sfx} / \mathrm{sfx}$ mice, heart damage has been reported in animal models lacking Gulo activity. ${ }^{36}$

AA Promotes $5 \mathrm{mC}$ Oxidation and Demethylation in Mice. Having shown that AA can regulate the formation of $5 \mathrm{hmC}$ in cultured cells, we next examined whether AA can affect $5 \mathrm{mC}$ oxidation in mammals. Although most animals have an ability to synthesize AA by themselves, humans have to depend upon dietary AA (or $\mathrm{Vc}$ ) due to an inherited mutation in the gene that encodes L-gulonolactone oxidase (Gulo), which is a key and ultimate enzyme of AA biosynthesis. ${ }^{37}$ To simulate human dependence upon AA, we tested an animal model using homozygote $\mathrm{sfx} / \mathrm{sfx}$ (spontaneous fracture) mice, which are deficient in AA synthesis because of a deletion in the Gulo gene. $^{36}$ We observed that AA supplementation significantly increased the level of $5 \mathrm{hmC}$ in adult $\mathrm{sfx} / \mathrm{sfx}$ mouse tissues (Figure 7A). Moreover, AA reduced the level of $5 \mathrm{mC}$ in the

\section{A}

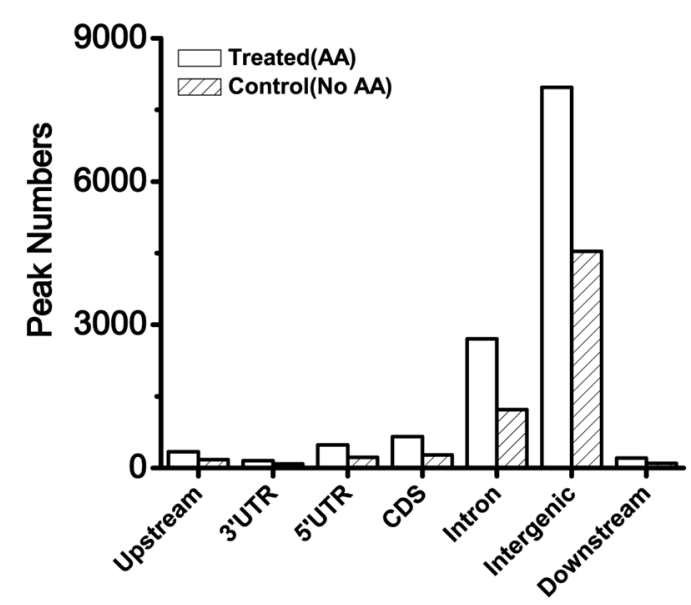

B

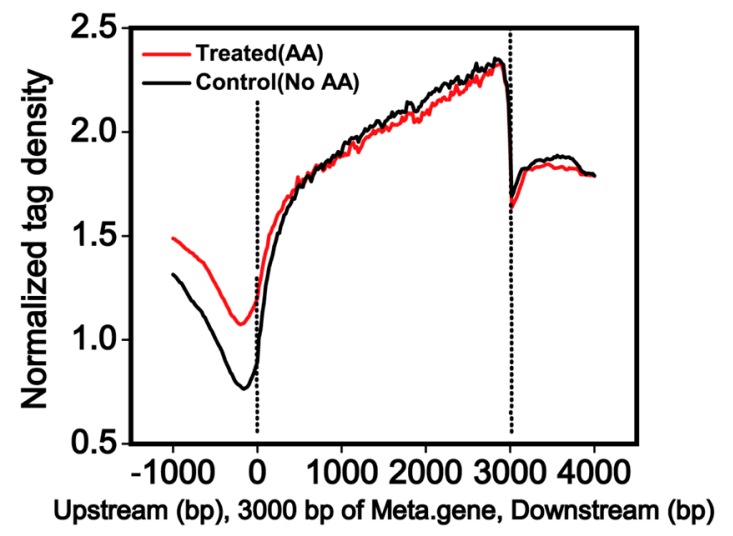

Figure 6. (A) Distribution of $5 \mathrm{hmC}$ in different gene features and (B) the average gene profile. 
A

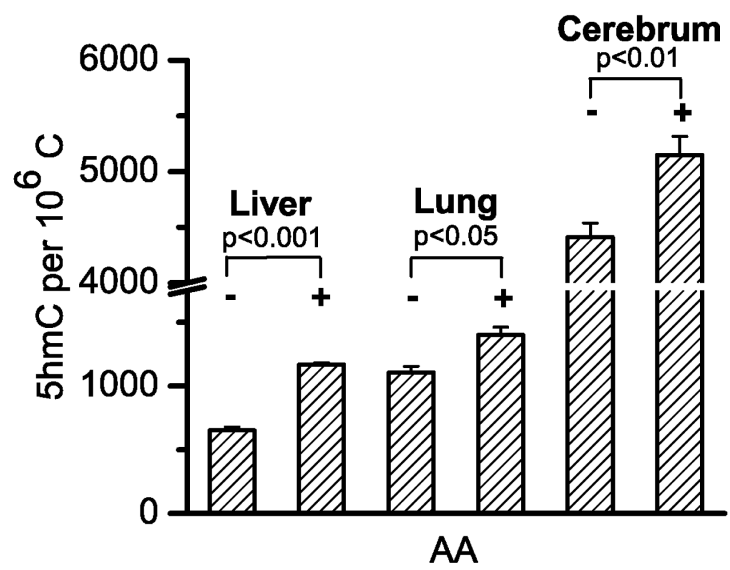

B

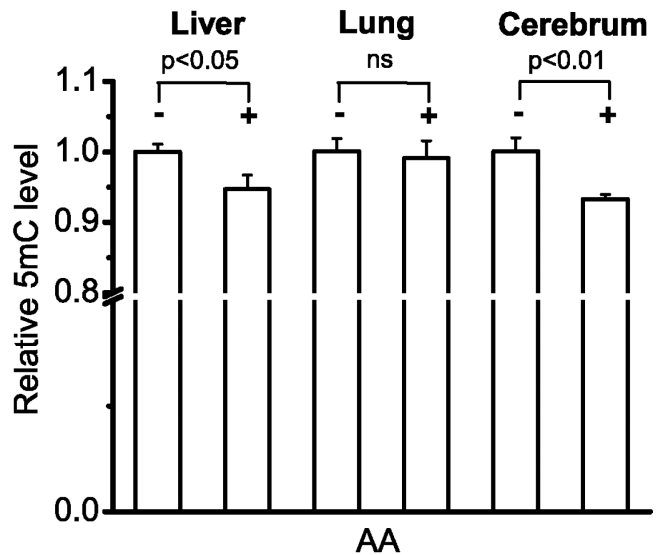

Figure 7. AA promotes oxidative DNA demethylation in a mouse model deficient in AA synthesis. The levels of (A) 5 hmC and (B) 5mC in mice without and with dietary AA supplementation were compared. "ns" indicates no significant difference. (Student $t$ test was used for evaluation of statistical significance.).

liver $(P<0.05, t$ test $)$ and in the cerebrum $(P<0.01, t$ test $)$ (Figure $7 \mathrm{~B})$. These results clearly show that $\mathrm{AA}$ regulates the levels of $5 \mathrm{mC}$ and $5 \mathrm{hmC}$ in mammals.

The measured $5 \mathrm{hmC}$ level in the cerebrum is $4-8$ times higher than in other two tissues (liver and lung). This is consistent with previous work showing the highest abundance of $5 \mathrm{hmC}$ in the central nervous system. ${ }^{22}$ Coincidently, brain is the most enriched tissue for AA due to the high expression of AA-specific transporter SVCT2. ${ }^{38}$ The level of AA is about 40 times higher in brain (1-2 $\mathrm{mM})$ than that in plasma in normal mice. $^{39}$ Previous work showed that AA withdrawal (for three weeks) could not eliminate AA from brain and almost half of AA was retained. ${ }^{40}$ Surprisingly, the decrease in the $5 \mathrm{hmC}$ level was also observed in the cerebrum of AA-withdrawn mice $(P<$ $0.01, t$ test, Figure $7 \mathrm{~A})$, suggesting a sensitivity of $5 \mathrm{hmC}$ formation to the AA change. Our previous work showed that the brain size of $\mathrm{sfx} / \mathrm{sfx}$ mice is 1.7 times as large as that of normal mice without AA supplement. ${ }^{36}$ Here, our results of GO analysis showed the involvement of AA in cerebellum development by enriching $5 \mathrm{hmC}$ in genes of ATP7A, ATP2B2, DAB1, AGTPBP1, MTPN, ATG7, MYO16, GAS1, WNT7A, and KLHL1 (Supporting Information, Figure S13B and Supporting Information, Excel Tables S1 and S2).

Taken together, these results may suggest an important role of AA-regulated $5 \mathrm{hmC}$ formation in brain development.

\section{DISCUSSION}

Here, we demonstrate that AA can remarkably improve the efficiency of iterative $5 \mathrm{mC}$ oxidation by directly enhancing the catalytic activity of Tet dioxygenases, thereby regulating the dynamics of DNA methylation. Mechanistically, AA may promote replication-dependent and passive DNA demethylation by enhancing $5 \mathrm{hmC}$ formation ${ }^{16}$ and accelerate active DNA demethylation by enhancing formation of $5 \mathrm{fC}$ and $5 \mathrm{caC}$. The mechanism on the acceleration of active DNA demethylation by AA may partially explain early and recent contradicting observations on rapid and active DNA demethylation. $^{10,11,17-19,41-44}$ By acceleration of DNA demethylation, AA can erase two-fifths of $5 \mathrm{mC}$ in the ES cells genome, which would not be achieved by active but AA-free Tet proteins. This suggests that the rate of DNA demethylation is crucial for both the maintenance and the changes of stable but reversible $5 \mathrm{mC}$ landscape.

Since it is a vital nutrient widely distributed but with varying concentrations in various tissues, AA could be exploited by nature to regulate the dynamics of DNA methylation in mammals. To the best of our knowledge, this is the first report on the direct linkage of AA, Tet, and DNA methylation.

Aberrant DNA methylation occurs in a number of diseases, including cancers, neurodevelopmental disorders, neurodegenerative and neurological diseases, and autoimmune diseases. ${ }^{45}$ Many genes involved in the main pathways (DNA repair, Ras signaling, cell cycle control, p53 network, and apoptosis) are transcriptionally inactivated by the hypermethylation at specific $\mathrm{CpG}$ islands (located in promoters) in cancer cells. ${ }^{45}$ Recently, it was reported that the silencing of microRNA by promoter hypermethylation is not only linked to cancer but also to metastasis. ${ }^{46}$ Interestingly, the reduced $5 \mathrm{hmC}$ level was observed in the hematopoietic malignancies and a broad range of solid tumors. ${ }^{23,47}$ These observations may indicate a critical role of the impaired regulation machinery on $5 \mathrm{mC}$ oxidation and DNA demethylation in the disease development. Potentially, AA might be an important defense by reducing the risks of promoter hypermethylation and maintaining the $5 \mathrm{hmC}$ level through the mechanism revealed in this work.

Our findings may suggest some unexplored nutrition values of AA for affecting DNA methylation. Besides its well-known function as an important water-soluble antioxidant, AA may modulate gene expression, induce differentiation of several mesenchymal cell types, and promote proliferation. ${ }^{48}$ Since these processes mostly require changes in methylation patterns, our findings on AA-enhanced oxidation of $5 \mathrm{mC}$ might account for these biological functions. Our GO and enrichment analysis also suggest that AA may regulate differentiation and organ development through its effect on $5 \mathrm{hmC}$ formation.

Notably, AA-regulated $5 \mathrm{hmC}$ formation may be critical for brain development as indicated by GO analysis showing 10 brain development-related genes with enriched $5 \mathrm{hmC}$ (Supporting Information, Figure S13B, Excel Table S1). This is also supported by the observations of reduced $5 \mathrm{hmC}$ in mouse cerebrum (this work) and phenotypically increased size of mouse brain caused by AA deficiency. ${ }^{36}$ In fact, the dynamics of DNA methylation are altered in neurological disorders. ${ }^{49}$ 
Recently, by microarray analysis, Suzlwach et al. found no significant increase in Tet family gene expression during neurodevelopment although $5 \mathrm{hmC}$ markedly increased from the early postnatal stage to adulthood. ${ }^{49}$ The observation hinted an additional factor required for regulating the $5 \mathrm{hmC}$ formation in neurons. Our work suggests that AA may partly contribute to the dynamics of DNA methylation in brain development.

We found that the enhancement of $5 \mathrm{mC}$ oxidation is due to the interaction of AA with the CD of Tet 1 and Tet 2 proteins. Therefore, AA can play an important role in ES self-renewal, normal myelopoiesis, myeloid leukemia and glomas, and the mammalian epigenome, for which the catalytic activities of Tet 1 and Tet 2 are crucial. ${ }^{23,50-52}$ Since all three Tet proteins share a high degree of homology within their CDs, ${ }^{53,54}$ our findings should be extendable to Tet3, which is critical for epigenetic reprogramming of fertilized zygotes and somatic nuclear programming in animal clones. ${ }^{19}$ This may implicate the involvement of AA in the key functions of Tet 3 . Indeed, AA can improve the speed and efficiency of human and mouse iPSC generation by defined factors. ${ }^{25,27,28}$ Furthermore, our Tet1/ Tet2 double knockout study clearly supports an important role of AA in the DNA demethylation of somatic cells and ES cells by enhancing Tet-mediated $5 \mathrm{mC}$ oxidation.

In conclusion, we discovered that $\mathrm{AA}$ can stimulate the oxidation of 5-methylcytosine by directly enhancing the catalytic activity of Tet dioxygenases probably through noncovalent interaction-induced change in enzyme dynamics and/or iron(II) recycling. AA thereby promotes replicationdependent (passive) DNA demethylation by increasing $5 \mathrm{hmC}$ formation and replication-independent active DNA demethylation by increasing $5 \mathrm{fC}$ and $5 \mathrm{caC}$ formation, regulating the dynamics of genome-wide DNA methylation in mammals. Through this mechanism, AA may potentially regulate a plethora of biological functions. The findings were also confirmed using Tet-transfected and deleted cells and using model animals deficient in ascorbic acid synthesis.

\section{METHODS}

UHPLC-MS/MS Analysis. Genomic DNA was extracted from the cultured cells using a genomic DNA purification kit (Promega, Madison, WI) according to the manufacturer's instructions. The extracted DNA $(10 \mu \mathrm{g})$ was digested to nucleosides with 1.0 U DNase $\mathrm{I}, 2.0 \mathrm{U}$ calf intestinal phosphatase, and $0.005 \mathrm{U}$ snake venom phosphodiesterase I at $37{ }^{\circ} \mathrm{C}$ overnight. The digests were filtered by ultrafiltration tubes to remove the enzymes and then were subjected to UHPLC-MS/MS analysis for detection of $5 \mathrm{mC}, 5 \mathrm{hmC}, 5 \mathrm{fC}$, and $5 \mathrm{caC}$. The stable isotope $5^{\prime}$-(methyl-d3) $2^{\prime}$-deoxycytidine $\left(\left[{ }^{2} \mathrm{D}_{3}\right] 5 \mathrm{mC}\right)$ was used as an internal standard for calibrating UHPLC-MS/MS quantitation of $5 \mathrm{mC}$.

Analysis of $5 \mathrm{mC}$ and its oxidation products was performed with a Zorbax Eclipse plus C18 column $(2.1 \mathrm{~mm} \times 100 \mathrm{~mm}, 1.8 \mu \mathrm{m}$, Agilent $)$ for separation and electrospray MS/MS (Agilent 6410B, Santa Clara, CA) for detection in the positive ion mode.

In Vitro Oxidation Reactions. The methylated DNA $(0.5 \mu \mathrm{g})$ was incubated with the purified Tet $2 \mathrm{CD}$ or Tet $1 \mathrm{CD}(0.25 \mu \mathrm{g})$ in 100 $\mu \mathrm{L}$ of HEPES buffer (50 mM HEPES, pH 8.0, $50 \mathrm{mM} \mathrm{NaCl}, 1 \mathrm{mM} 2$ oxoglutarate, $10 \mu \mathrm{M} \mathrm{FeCl}_{2}, 1 \mathrm{mM}$ ATP, $1 \mathrm{mM}$ DTT, and 0-500 $\mu \mathrm{M}$ AA) at $37^{\circ} \mathrm{C}$. After reaction for $2 \mathrm{~h}$, the Tet $2 \mathrm{CD}$ was inactivated by heating for $5 \mathrm{~min}$ at $95{ }^{\circ} \mathrm{C}$. The reacted DNA was then subjected to enzymatic digestion followed by UHPLC-MS/MS analysis.

Binding Assay. Interaction of AA with Tet proteins was studied by intrinsic fluorescence quenching assays. Samples were prepared as in vitro oxidation reactions except that no methylated DNA was added.
After incubation for $10 \mathrm{~min}$, the samples were subjected to fluorescence analysis.

All fluorescence measurements were performed on a Fluoromax-4 spectrometer (Horiba Jobin Yvon Inc., Edison, NJ) at room temperature. Intrinsic fluorescence emission spectra of the Tet2 CD were monitored by exciting the sample at $280 \mathrm{~nm}$ and measuring the emission from 290 to $400 \mathrm{~nm}$. Slits for both excitation and emission were set at $5 \mathrm{~nm}$. The integration time was set as $0.1 \mathrm{~s}$.

The binding constant was estimated according to the modified Stern-Volmer equation: ${ }^{55,56}$

$$
\frac{\mathrm{RF}_{0}}{\Delta \mathrm{RF}}=\frac{1}{f K} \times[Q]^{-1}+\frac{1}{f}
$$

where $\mathrm{RF}_{0}$ and $\mathrm{RF}$ are the relative fluorescence intensities of protein in the absence and presence of quencher, respectively. $[Q]$ is the concentration of the quencher. $\Delta \mathrm{RF}$ is equal to $\mathrm{RF}_{0}-\mathrm{RF}$. $f$ is the fractional maximum fluorescence intensity of the protein. $K$ is the quenching constant and is also considered as the binding constant. ${ }^{56}$

By plotting $\mathrm{RF}_{0} / \Delta \mathrm{RF}$ versus $[Q]^{-1}$, a linear curve could be obtained with a slope of $1 /(f K)$ and an intercept of $1 / f$. The binding constant was estimated from the quotient of the intercept and the slope.

\section{ASSOCIATED CONTENT}

\section{S Supporting Information}

Details of the materials, methods, and experimental procedures as well as additional information as noted in the text. This material is available free of charge via the Internet at http:// pubs.acs.org.

\section{R Related Articles}

During the revision of this manuscript, Dr. Gaofeng Wang's lab (at the University of Miami) reported a stimulation of Tetmediated hydroxylation of $5 \mathrm{mC}$ by ascorbate at cellular level (http://www.jbc.org/cgi/doi/10.1074/jbc.C113.464800).

\section{AUTHOR INFORMATION}

\section{Corresponding Author}

hlwang@rcees.ac.cn

\section{Notes}

The authors declare no competing financial interest.

\section{ACKNOWLEDGMENTS}

We thank Prof. Michael Weinfeld at the University of Alberta for his discussion and comments. This study was supported by grants from the Ministry of Science and Technology of China (2011CB936001 and 2009CB421065) and National Science Foundation of China (21077129 and 21125523) to W.H.

\section{REFERENCES}

(1) Wilmut, I.; Shnieke, A. E.; McWhir, J.; Kind, A. J.; Campbell, K. H. S. Nature 1997, 385, 810.

(2) Mikkelsen, T. S.; Hanna, J.; Zhang, X.; Ku, M.; Wernig, M.; Schorderet, P.; Bernstein, B. E.; Jaenisch, R.; Lander, E. S.; Meissner, A. Nature 2008, 454, 49.

(3) Jullien, J.; Pasque, V.; Halley-Stott, R. P.; Miyamoto, K.; Gurdon, J. B. Nat. Rev. Mol. Cell Biol. 2011, 12, 453.

(4) Reik, W.; Dean, W.; Walter, J. Science 2001, 293, 1089.

(5) Mayer, W.; Niveleau, A.; Walter, J.; Fundele, R.; Haaf, T. Nature 2000, 403, 501.

(6) Oswald, J.; Engemann, S.; Lane, N.; Mayer, W.; Olek, A.; Fundele, R.; Dean, W.; Reik, W.; Walter, J. Curr. Biol. 2000, 10, 475.

(7) Rideout, I. W.; Eggan, K.; Jaenisch, R. Science 2001, 293, 1093.

(8) Simonsson, S.; Gurdon, J. Nat. Cell Biol. 2004, 6, 984.

(9) Guo, J. U.; Su, Y.; Zhong, C.; Ming, G.-1.; Song, H. Cell 2011, $145,423$. 
(10) Kangaspeska, S.; Stride, B.; Métivier, R.; Polycarpou-Schwarz, M.; Ibberson, D.; Carmouche, R. P.; Benes, V.; Gannon, F.; Reid, G. Nature 2008, 452, 112.

(11) Métivier, R.; Gallais, R.; Tiffoche, C.; Le Péron, C.; Jurkowska, R. Z.; Carmouche, R. P.; Ibberson, D.; Barath, P.; Demay, F.; Reid, G.; et al. Nature 2008, 452, 45.

(12) Tahiliani, M.; Koh, K. P.; Shen, Y.; Pastor, W. A.; Bandukwala, H.; Brudno, Y.; Agarwal, S.; Iyer, L. M.; Liu, D. R.; Aravind, L.; Rao, A. Science 2009, 324, 930.

(13) Wu, H.; Zhang, Y. Genes Dev. 2011, 25, 2436.

(14) He, Y. F.; Li, B. Z.; Li, Z.; Liu, P.; Wang, Y.; Tang, Q.; Ding, J.; Jia, Y.; Chen, Z.; Li, L.; et al. Science 2011, 333, 1303.

(15) Ito, S.; Shen, L.; Dai, Q.; Wu, S. C.; Collins, L. B.; Swenberg, J. A.; He, C.; Zhang, Y. Science 2011, 333, 1300.

(16) Inoue, A.; Zhang, Y. Science 2011, 334, 194.

(17) Iqbal, K.; Jin, S. G.; Pfeifer, G. P.; Szabó, P. E. Proc. Natl. Acad. Sci. U.S.A. 2011, 108, 3642.

(18) Wossidlo, M.; Nakamura, T.; Lepikhov, C.; Marques, C. J.; Zakhartchenko, V.; Boiani, M.; Arand, J.; Nakano, T.; Reik, W.; Walter, J. Nat. Commun. 2011, 2, 241.

(19) Gu, T. P.; Guo, F.; Yang, H.; Wu, H.-P.; Xu, G.-F.; Liu, W.; Xie, Z.-G.; Shi, L.; He, X.; Jin, S.-g.; et al. Nature 2011, 477, 606.

(20) Pfaffeneder, T.; Hachner, B.; Truß, M.; Münzel, M.; Müller, M.; Deiml, C. A.; Hagemeier, C.; Carell, T. Angew. Chem., Int. Ed. 2011, 123, 7146.

(21) Bhutani, N.; Burns, D. M.; Blau, H. M. Cell 2011, 146, 866.

(22) Globisch, D.; Münzel, M.; Müller, M.; Michalakis, S.; Wagner, M.; Koch, S.; Brückl, T.; Biel, M.; Carell, T. PLoS ONE 2011, 5, e15367.

(23) Tan, L.; Shi, Y. G. Development 2012, 139, 1895.

(24) Gorres, K. L.; Raines, R. T. Crit. Rev. Biochem. Mol. Biol. 2010, 45, 106.

(25) Stadtfeld, M.; Apostolou, E.; Ferrari, F.; Choi, J.; Walsh, R. M.; Chen, T.; Ooi, S. S. K.; Kim, S. Y.; Bestor, T. H.; Shioda, T. Nat. Genet. 2012, 44, 398.

(26) Chung, T. L.; Brena, R. M.; Kolle, G.; Grimmond, S. M.; Berman, B. P.; Laird, P. W.; Pera, M. F.; Wolvetang, J. Stem Cells 2010, $28,1848$.

(27) Esteban, M. A.; Wang, T.; Qin, B. M.; Yang, J.; Qin, D.; Cai, J.; Li, W.; Weng, Z.; Chen, J.; Ni, S.; et al. Cell Stem Cell 2010, 6, 71.

(28) Wang, T.; Chen, K. S.; Zeng, X. M.; Yang, J.; Wu, Y.; Shi, X.; Qin, B.; Zeng, L.; Esteban, M. A.; Pan, G.; Pei, D. Cell Stem Cell 2011, 9, 575.

(29) Chung, T. L.; Turner, J. P.; Thaker, N. Y.; Kolle, G.; CooperWhite, J. J.; Grimmond, S. M.; Pera, M. F.; Wolvetang, E. J. Stem Cells 2010, 28, 1782.

(30) Mackenzie, E. L.; Iwasaki, E.; Tsuji, Y. Antioxid. Redox Signaling 2008, 10, 997.

(31) Lakowicz, J. R. Principles of Fluorescence Spectroscopy, 3rd ed.; Springer-Verlag: Berlin, Germany, 2006.

(32) Bleijlevens, B.; Shivarattan, T.; van den Boom, K. S.; de Haan, A.; van der Zwan, G.; Simpson, P. J.; Matthews, S. J. Biochemistry 2012, 51, 3334.

(33) Song, C. X.; Szulwach, K. E.; Fu, Y.; Dai, Q.; Yi, C.; Li, X.; Li, Y.; Chen, C.-H.; Zhang, W.; Jian, X.; et al. Nat. Biotechnol. 2011, 29, 68.

(34) Maiti, A.; Drohat, A. C. J. Biol. Chem. 2011, 286, 35334.

(35) Jackson, M.; Krassowska, A.; Gilbert, N.; Chevassut, T.; Forrester, L.; Ansell, J.; Ramsahoye, B. Mol. Cell. Biol. 2004, 24, 8862.

(36) Jiao, Y.; Li, X. M.; Beamer, W. G.; Yan, J.; Tong, Y.; Goldowitz, D.; Roe, B.; Gu, W. Mamm. Genome 2005, 16, 20.

(37) Nishikimi, M.; Yagi, K. Am. J. Clin. Nutr. 1991, 54, $1203 \mathrm{~S}$.

(38) May, J. M. Vitamin C transport and its role in the central nervous system. In Water Soluble Vitamins, Subcellular Biochemistry 56; Stanger, O., Ed.; Springer: New York, 2012; Chapter 6, pp 85-99.

(39) Maeda, N.; Hagihara, H.; Nakata, Y.; Hiller, S.; Wilder, J.; Reddick, R. Proc. Natl. Acad. Sci. U.S.A. 2000, 97, 841.

(40) Kim, H.; Bae, S.; Yu, Y.; Kim, Y.; Kim, H. R.; Hwang, Y. I.; Kang, J. S.; Lee, W. J. Immune Network 2012, 12, 18.

(41) Bruniquel, D.; Schwartz, R. H. Nat. Immunol. 2003, 4, 235.
(42) Paroush, Z.; Keshet, I.; Yisraeli, J.; Cedar, H. Cell 1990, 63, 1229.

(43) Zhang, F.; Pomerantz, J. H.; Sen, G.; Palermo, A. T.; Blau, H. M. Proc. Natl. Acad. Sci. U.S.A. 2007, 104, 4395.

(44) Martinowich, K.; Hattori, D.; Wu, H.; Fouse, S.; He, F.; Hu, Y.; Fan, G.; Sun, Y. E. Science 2003, 302, 890.

(45) Portela, A.; Esteller, M. Nat. Biotechnol. 2010, 28, 1057.

(46) Lujambio, A.; Ropero, S.; Ballestar, E.; Fraga, M. F.; Cerrato, C.; Setién, F.; Casado, S.; Suarez-Gauthier, A.; Sanchez-Cespedes, M.; Gitt, A.; et al. Cancer Res. 2007, 67, 1424.

(47) Jin, S. G.; Jiang, Y.; Qiu, R.; Rauch, T. A.; Wang, Y.; Schackert, G.; Lu, Q.; Pfeifer, G. P. Cancer Res. 2011, 71, 7360.

(48) De Tullio, M. C. Beyond the antioxidants: the double life of vitamin C. In Water Soluble Vitamins, Subcellular Biochemistry 56; Stanger, O., Ed.; Springer: New York, 2012; Chapter 4, pp49-65.

(49) Szulwach, K. E.; Li, X. K.; Li, Y. J.; Song, C.-X.; Wu, H.; Dai, Q.; Irier, H.; Upadhyay, A. K.; Gearing, M.; Levey, A. I.; et al. Nat. Neurosci. 2011, 14, 1607.

(50) Koh, K. P.; Yabuuchi, A.; Rao, S.; Huang, Y.; Cunniff, K.; Nardone, J.; Laiho, A.; Tahiliani, M.; Sommer, C. A.; Mostoslavsky, G.; et al. Cell Stem Cell 2011, 8, 200.

(51) Ito, S.; D’Alessio, A. C.; Taranova, O. V.; Hong, K.; Sowers, L. C.; Zhang, Y. Nature 2010, 466, 1129.

(52) Branco, M. R.; Ficz, G.; Reik, W. Nat. Rev. Genet. 2012, 3, 7.

(53) Iyer, L. M.; Tahilian, M.; Rao, A.; Aravind, L. Cell Cycle 2009, 8, 1698.

(54) Loenarz, C.; Schofield, C. J. Chem. Biol. 2009, 16, 580.

(55) Eftink, M. R.; Ghiron, C. A. Anal. Biochem. 1981, 114, 199.

(56) Sułkowska, A. J. Mol. Struct. 2002, 614, 227. 